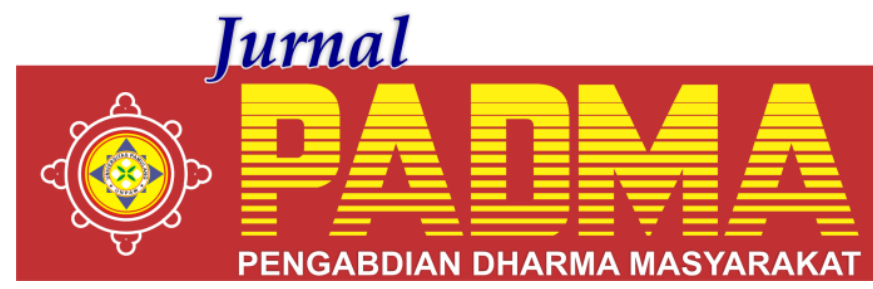

VOLUME 1, NOMOR 1, JANUARI 2021

\title{
PENYULUHAN MOTIVASI DAN PENGEMBANGAN SDM UNTUK MENINGKATKAN KEMANDIRIAN WIRAUSAHA HOME INDUSTRY MEJA KURSI DARI BAN BEKAS
}

\author{
${ }^{1 *}$ Asep Muhammad Lutfi, ${ }^{2}$ Ali Maddinsyah, ${ }^{3}$ Veritia, ${ }^{4}$ Endang Kustini, ${ }^{5}$ Eni Puji Astuti \\ Universitas Pamulang, Tangerang Selatan, Banten, Indonesia \\ *dosen02469@unpam.ac.id
}

\begin{abstract}
Abstrak
Sampah yang di daur ulang dan diberdayakan dapat menjadi peluang atau berpotensi menjadi dapat meningkatkan ekonomi keluarga. Persediaan barang bekas tidak perlu dikhawatirkan, hanya bermitra dengan bank sampah, maka barang bekas akan sangat mudah diperoleh. Jika barang-barang bekas ini dimanfaatkan dan didaur ulang sedemikian rupa, selain mendatangkan manfaat dan meningkatkan ekonomi keluarga, juga membantu mengatasi permasalahan sampah yang menjadi pekerjaan rumah (PR) bagi suatu pemerintahan terutama kota-kota besar di Indonesia. Untuk itu, pengelolan barang bekas menjadi tanggung jawab kita semua, sebagai sumber atau penghasil sampah. Pada dasarnya sampah dihasilkan dari kegiatan atau aktivitas makhluk hidup. Untuk aktivitas tumbuhan dan hewan justru mendatangkan manfaat bagi makhluk yang lain, tetapi aktivitas manusia dalam kehidupan sehari-hari justru mengahsikan sampah yang sangat berbahaya bagi lingkungan atau ekosistem yang lain, seperti sampah plastic, sampah kaleng, kaca dan sebagainya, belum lagi limbah industry yang mengandung zat adiktif. Jika barang bekas ini dimanfaatkan dan bernilai ekonomi maka dapat menjadi sumber penghasilan bagi keluarga atau dengan bahasa lain dapat meningkatkan ekonomi keluarga. Daur ulang barang bekasini dapat dikemas dalam wirausaha home industry. Sekarang inisudah banyak pelaku home industry daur ulang barang bekas, karena masyarakat sudah mulai sadar tidak mudah mendapatkan pekerjaan ditengah-tengah pesaing yang sangat kompetitif. Meskipun untuk menjadi wirausahawan tidak cukup hanya bermodalkan tekat menjadi wirausahawan tetapi butuh komitmen dan motivasi untuk menjadi wirausahawan. Karena untuk merintis usaha atau membuka usaha home indutry tidaklah semudah membalikan telapak tangan. Jatuh bangun dalam usaha itu hal yang sangat wajar, dan butuh tekat yang sangat kuat untuk tetap eksis, apalagi bahan bakunya barang bekas, terkadang masyarakat masih memandang rendah hasil karya yang berbahan baku barang beka
\end{abstract}

Kata Kunci: Wirausaha, Home Industry, Ekonomi Keluarga Sekitar.

\begin{abstract}
Recycled and empowered waste can be an opportunity or have the potential to improve the family economy. The stock of used goods is nothing to worry about, just partnering with a waste bank, so used goods will be very easy to obtain. If these used and recycled items are used and recycled in such a way, in addition to bringing benefits and improving the family's economy, they will also help overcome the waste problem which is homework for a government, especially big cities in Indonesia. For this reason, the management of used goods is the responsibility of all of us, as a source or producer of waste. Basically, waste is generated from the activities or activities of living things. For plant and animal activities, it actually brings benefits to other creatures, but human activities in everyday life actually produce waste that is very dangerous to the environment or other ecosystems, such as plastic waste, cans, glass and so on, not to mention industrial waste that is contains addictive substances. If these used goods are used and have economic value, they can be a source of income for the family or in other languages it can improve the family's economy. Recycled used goods can be packaged in the home industry entrepreneurship. Now there are many home industry players who recycle used goods, because people have started to realize that it is not easy to get a job amidst very competitive competitors. Even though to become an entrepreneur, it is not enough to have the determination to become an entrepreneur, but it takes commitment and motivation to become an entrepreneur. Because starting a business or opening a home industry business is not as easy as turning your hand. The ups and downs in a business are very natural things, and it takes a very strong determination to continue to exist, especially when the raw materials are used goods, sometimes people still look down on the work made of handmade goods
\end{abstract}

Keywords: Entrepreneurship, Home Industry, Family Economy Around. 


\section{PENDAHULUAN}

Wirausaha home industry berbahan baku barang bekas tentu butuh daya juang yang luar biasa, karena untuk memasarkan hasil produksinya harus bersaing dengan produksi barang baru yang secara harga juga mampu bersaing. Tentu masyarakat akan cenderung memilih barang baru bukan barang daur ulang.

Hal ini yang menyebabkan perkembangan usaha pada home industry daur ulang barang bekas agak berat, sulit diukur dan sulit berkembang karena pesaingnya adalah home industry barang baru. Masyarakat masih belum familier dan belum teersosialisasi kepada masyarakat bahwa barang bekas yang sudah di daur ulang juga barang baru. Permasalahan yang lain, masyarakat kurang memiliki greget dan daya kreativitas untuk mengubah barang bekas menjadi barang yang bernilai manfaat dan bernilai ekonomis. Beberapa contoh barang hasil daur ulang barang bekas.

Pada kegiatan pengabdian kepada masyarakat ini, pengusul tertarik untuk memberikan penyuluhan penyuluhan wirausaha home industry untuk meningkatkan ekonomi keluarga dengan daur ulang barang bekas karena pengusul melihat potensi yang sangat besar home industry ini untuk dikembangkan. bahan baku atau barang bekas yang mudah dan murah diperoleh adalah barang bekas plastic, selain itu plastic juga merupakan bahan yang tidak mudah diuraikan, dan untuk dihancurkanpun akan sulit, oleh karenanya akan lebih bijaksana kalau didaur ulang dijadikan barang baru yang bernilai guna dan bernilai ekonomis. Plastik merupakan bahan yang tidak mudah diuraikan oleh tanah, maka akan menjadi masalah besar jika tidak di daur ulang ataupun dimanfaatkan kembali.

Daur ulang plastik ini sangat berpotensi untuk dikembangkan dan diarahkan untuk meningkatkan ekonomi keluarga, karena setelah mendapat sentuhan kreatifitas, plastic-plastik ini dapat disulap menjadi peralatan dapur, vas bunga, tempat alat tulis kantor. Sifat plastik awet dan nyaman tidak bisa karatan dan relative lebih ringan. juga mempunyai peluang usaha yang prospektif. Potensi usaha ini juga didukung oleh mudahnya memperoleh bahan baku botol plastik bekas dengan harga yang relatif murah dan mudah diperoleh. Hal ini dikarenakan banyak makanan atau minuman kemasan plastic yang beredar di masyarakat sehingga akan sangat mudah dan murah untuk mendapatkan barang bekas plastic. Karena tidak tertangani dengan baik, akhir- akhir ini banyak bantak sungai ataupun lahan kosong berubah wajah menjadi sungai plastic, barang bekas dari kemasan makanan dan minuman. Artinya, bahan baku barang bekas plastic akan tercukupi dengan baik, tinggal pemanfaatannya butuh kreativitas tingkat tinggi agar plastic-plastik bekas dapat di ubah menjadi berbagai bentuk barang yang bernilai guna dan bernilai ekonomis. Apalagi jumlah penduduk yang sangat padat dan tingkat konsumsi yang tinggi akan memberikan peluang untuk memperoleh bahan baku barang bekas dengan mudah. Meskipun tidak semua plastik bekas dapat digunakan namun masih relative mudah memperoleh bahan baku karena pengepul plastik bekas juga sudah banyak pelakunya, jadi para pengrajin atau pengusaha ekonomi kreatif plastik dijadikan peralatan dapur atau hiasan tidak khawatir terjadi kelangkaan bahan baku plastik bekas. Program pemerintah dengan gerakan peduli sampah dan minim sampah yang dimulai dari rumah tangga perlu dukungan dari semua pihak agar tujuan pengelolaan sampah dapat diwujudkan.

Desa Cidokom merupakan bagian wilayah dari Kecamatan Gunung Sindur Kabupaten Bogor Jawa Barat, masih relative tradisional dalam penanganan barang bekas (sampah) yaitu dengan cara dibakar atau dibuang disungai. Program bank sampah yang digerakkan belum secara optimal dapat diberdayakan di Desa Cidokom, masyarakat lebih suka membuang sampah dipekarangan rumahnya atau dibakar jika sudah banyak. Juga belum terkondisikan bahwa sampah harus dibuang pada tempatnya, yaitu tempat pembuangan akhir (TPA).

Sehingga barang bekas tetap menjadi sampah yang notabene sudah tidak bernilai secara ekonomis. Untuk itu melalui ibu-ibu PKK, program pengabdian kepada 
masyarakat hadir untuk memberikan penyuluhan kepada warga masyarakat bahwasanya barang bekas dapat difungsikan dan dimanfaatkan kembali dengan sentuhan kreatif agar dapat menjadi sumber penghasilan rumah tangga sehingga meningkatkan ekonomi keluarga. Dan pilihan lokasi di Desa Cidokom, karena pengusul melihat masyarakat setempat masih belum peduli terhadap kebersihan dan kesehatan lingkungan, teercermin dari perilaku masyarakat setempat yang masih membuang barang bekas disembarang tempat. Banyak waktu luang yang dapat difungsikan untuk lebih produkstif dengan aktif di kegiatan masyarakat seperti PKK untuk bersosialisasi atau penegmbangan diri dari warga masyarakat setempat. Organisasi social masyarakat PKK merupakan wadah kreasi ibu-ibu untuk mengembangkan bakat dan minatnya. Tentu masih banyak hal yang harus disiapkan dan dikondisikan untuk menggerakkan masyarakat setempat agar lebih produktif Oleh karenanya, perlu perhatian dari aparatur setempat untuk mengembangkan potensi masyarakat. Permasalahan yang lain adalah tempat pemasaran hasil produksi dari daur ulang barang bekas ini juga masih belum familiar dimasyarakat dan jaringannya juga masih sempit, dengan begitu membutuhkan pasar yang luas untuk memasarkan hasil produksinya. Kebanyakan masyarakat masih memandang sebelah mata hasil-hasil produksi dari daur ulang sampah terlebih kebiasaan mereka masih memperlakukan barang bekas sabagai sampah sehingga masih dibuang disembarang tempat atau dibakar. Berdasarkan latar belakang di atas, pengusul pengabdian kepada masyarakat tertarik untuk berkontribusi membangun masyarat warga Desa Cidokom dengan menumbuhkan produkstivitas mereka melalaui penyuluhan Wirausaha Home Industry untuk Meningkatkan Ekonomi Keluarga Dengan Daur Ulang Barang Bekas.

Pengabdian kepada masyarakat diharapkan dapat memberikan manfaatbagi masyarakat sesuai dengan tujuan dari dilaksanakan kegiatan ini.

Manfaat teoritis dari pengabdian kepada masyarakat ini untuk mengembangkan wawasan dan pengetahuan pentingnya pengembangankualitas sumber daya manusia.

Manfaat Empiris Tujuan lain dari pengabdian kepada masyarakat ini adalah untuknmemberikan manfaat secara empiris bagi Mahasiswa Hasil pengabdian kepada masyarakat ini nanti manfaat

umum diharapkan mampu dijadikan rujukan, referensi, dan acuan bagi mahasiswayang ingin menggali informasi lebih lanjut tentang pengembangan sumberdaya manusia.

Bagi Prodi Hasil pengabdian kepada masyarakat ini nanti diharapkan dapat digunakan untuk mengembangkan bahan ajar Manajemen Sumber Daya Manusia serta sebagai bahan rujukan mahasiswa yang sedang menyusun Tugas Akhir dengan materi terkait.

Bagi Peneliti Hasil pengabdian kepada masyarakat ini nanti diharapkan dapatdikembangkan pada proses pembelajaran materi MSDM

Bagi Masyarakat Hasil pengabdian kepada masyarakat ini nanti diharapkan dapatmenggerakkan masyarakat untuk mengembangkan kualitas sumber daya manusia.

\section{METODE}

Metode pelaksanaan memaparkan tahapan yang perlu dilakukan mulai dari perencanaan/ pengusulan hingga pelaporan dalam saru rangkaian kegiatan pelaksanaan pengabdian kepada masyarakat. Metode pelaksanaan dalam kegiatan pengabdian kepada masyarakat ini diawali dengan melakukan surve lokasi di desa Cidokom Kecamatan Gunung Sindur Kabupaten Bogor atas ketertarikan tim pengusul berdasarkan pengamatan sehari-hari, waktu kaum ibu-ibu habis untuk aktivitas yang kurang bermanfaat dalam kesehariannya, seperti main ke tetangga begitu anak sudah berangkat sekolah dan suami berangkat kerja.

\section{HASIL DAN PEMBAHASAN}

Penyuluhan wirausaha home industry untuk meningkatkan ekonomi keluarga dengan daur ulang barang bekas, hadir untuk memberikan pengetahuan, wawasan dan peluang yang sangat potensial dikembangkan, karena bahan bakunya murah dan mudah diperoleh. Obyek pada 
kegiatan pengabdian kepada masyarakat ini adalah pada ibu-ibu PKK RT.04 RW 03 Desa Cidokom Kecamatan Gunung Sindur Kabupaten Bogor Jawa Barat, karena pengusul pengabdian kepada masyarakat melihat potensi local baik dari sumber daya manusia yaitu ibu-ibu rumah tangga dan bahan baku dari barang bekas yang mudah dan murah diperoleh sehingga sangat memungkinkan untuk dikembangkan guna meningkatkan ekonomi keluarga masyarakat setempat.

Tujuan dari penyuluhan wirausaha home industry untuk meningkatkan ekonomi keluarga dengan daur ulang barang bekas agar masyarakat setempat dapat meningkatkan ekonomi keluarga dengan berkreasi, berkarya dan berdaya juang untuk mengubah barang bekas yang tidak bernilai secara ekonomis menjadi barang yang bernilai guna serta bernilai ekonomi tinggi. Oleh karena itu, melalui kegiatan pengabdian kepada masyarakat yang dilakukan oleh tim dosen dan mahasiswa Universitas Pamulang ini diharapkan dapat turut berkontribusi membangun desa Cidokom melalui ibu-ibu PKK nya berbagi pengetahuan, mendorong masyarakat untuk pengembangan sumberdaya yang dimiliki secara berkelanjutan untuk meningkatkan ekonomi keluarga.

Wirausaha home industry daur ulang barang bekas ini dimaksudkan dapat memberikan motivasi bagi masyarakat untuk meningkatkan kemampuannya dan berkarya sehingga mendatangkan manfaat bagi dirinya dan masyarakat sekitar. Daur ulang barang bekas ini dapat dikemas dalam wirausaha home industry. Sekarang ini sudah banyak pelaku home industry daur ulang barang bekas, karena masyarakat sudah mulai sadar tidak mudah mendapatkan pekerjaan ditengah-tengah pesaing yang sangat kompetitif. Meskipun untuk menjadi wirausahawan tidak cukup hanya bermodalkan tekat menjadi wirausahawan tetapi butuh komitmen dan motivasi untuk menjadi wirausahawan. Karena untuk merintis usaha atau membuka usaha home indutry tidaklah semudah membalikan telapak tangan. Jatuh bangun dalam usaha itu hal yang sangat wajar, dan butuh tekat yang sangat kuat untuk tetap eksis, apalagi bahan bakunya barang bekas, terkadang masyarakat masih memandang rendah hasil karya yang berbahan baku barang bekas.

\section{PENUTUP}

Dari kegiatan ini diharapkan dapat memberikan kontribusi membangun desa Cidokom melalui ibu-ibu PKK nya berbagi pengetahuan, mendorong masyarakat untuk pengembangan sumberdaya yang dimiliki secara berkelanjutan untuk meningkatkan ekonomi keluarga. Wirausaha home industry daur ulang barang bekas ini dimaksudkan dapat memberikan motivasi bagi masyarakat untuk meningkatkan kemampuannya dan berkarya sehingga mendatangkan manfaat bagi dirinya dan masyarakat sekitar.

\section{DAFTAR PUSTAKA}

Darwanto, 2015. Pengembangan Usaha Mikro Kecil dan Menengah (UMKM)

Notoadmodjo, 2007 Pendidikan dan Perilaku Kesehatan. Reneka Cipta. Jakarta. Cetakan ke 2.

Rozi, A., \& Sunarsi, D. (2020). The Influence of Motivation and Work Experience on Employee Performance at PT. Yamaha Saka Motor in South Tangerang. Jurnal Office, 5(2), 65-74.

Sejati, 2009. Pengelolaan Sampah Terpadu. Yogyakarta.

Sumantri (2010) Kesehatan Lingkungan. Kencana Prenada Media Group. Jakarta

Sunarsi, D., Kustini, E., Lutfi, A. M., Fauzi, R. D., \& Noryani, N. (2019). Penyuluhan Wirausaha Home Industry Untuk Meningkatkan Ekonomi Keluarga Dengan Daur Ulang Barang Bekas. BAKTIMAS: Jurnal Pengabdian pada Masyarakat, 1(4), 188-193.

Supriyadi, D., Syafitri, L. N. H., Widodo, S. F. A., Wahidi, R., Arinta, Y. N., Nabhan, F., ... \& Cahyono, Y. (2020). Innovation And Authentic Leadership Of Islamic University Lectures In Faculty Pharmacy Faculty: What Is The Role Of Psychological Capital?. Systematic Reviews in Pharmacy, 11(8), 383-393. 